\title{
El reto de las empresas peruanas: Aprender sobre la base de una misión compartida
}

\section{CPC Julio Palomino Silva}

Docente Auxiliar de la Facultad de Ciencias Contables

\section{RESUMEN:}

En estos momentos, ad portas de ingresar a funcionar el TLC con Estados Unidos y estar negociándose otros tratados con Canadá, China, Europa y otros paises, tenemos el reto de trabajar para un posible futuro de múltiples opciones; las empresas capaces de aprender concentran sus esfuerzos en desarrollar habilidades para pensar, crear e imaginar individualmente y con otros, generar relaciones constructivas entre las personas involucradas en los proyectos a desarrollarse y organizarse en forma continua, de acuerdo a una visión que cubra necesidades y proyectos que realizan. Dentro de este marco, es necesario comprender que las empresas tienen un gran reto por delante, que es el de adaptarse y aprender de otras organizaciones.

Palabras clave: Estrategias de la organización, planeación de empresas, misión, visión empresarial. 


\section{INTRODUCCIÓN}

El presente artículo tiene por finalidad el reto que tienen hoy las empresas en nuestro país, aprender de otras organizaciones bajo una misión compartida. El Perú, en estas últimas semanas, ha vivido un evento significativo como es la cumbre de AL-CUE, donde se han dado cita empresarios y mandatarios de América Latina, Europa y el Caribe. Las cifras macro y microeconómicas reflejan que nuestro país va por buen camino y que estamos aprendiendo la lección de que no puede haber desarrollo sin inversión y un compromiso empresarial de seguir apostando por lo nuestro; pero más allá de este compromiso, debemos aprender y seguir aprendiendo de otros modelos del mundo para hacer de las empresas nacionales organizaciones fuertes, y que puedan competir en un mercado cada vez más exigente. El viejo sueño de generar riqueza, perdurar más en el tiempo, disponer de productos o bienes que se consumen y mantienen su posición en el mercado, ¿no son razones suficientes para dirigir nuestras miradas hacia aquellas empresas que lo logran?

Estamos hablando de las «empresas capaces de aprender». ¿Cómo son?, ¿qué hacen?, ¿es posible aprender de su experiencia?

El término «empresa capaz de aprender», se fundamenta en el concepto de «Aprendizaje organizacional». Dixon (1994) lo define como el uso intencionado del proceso de aprendizaje a nivel individual, de grupo y del sistema para transformar de forma continua la organización con el propósito de satisfacer cada vez más a sus consumidores.

Los expertos coinciden al asegurar que bajo el denominador común de «empresas que aprenden» se identifican dos características esenciales comunes a todas ellas: han aprendido a adaptarse de forma rápida a los cambios y han desarrollado un estilo propio de ser y hacer que las diferencias no se manifiesten. En general son empresas de tamaño pequeńo o estructuradas en unidades interactivas, organizadas en función de tener autonomía y flexibilidad de pensamiento y actuación.

En el entorno actual, es el tiempo para las empresas que aprenden. Son ejemplo de empresas gigantes a nivel internacional como Levi's, Boehringer Ingelheim, Nissan, así como múltiples empresas medianas y pequeñas que buscan nuevos caminos para asegurar su eficiencia y posición en el mercado, en un mundo de cambios rápidos y críticos. El reto de satisfacer las necesidades de los consumidores, dando más y mejor, utilizando menos recursos, está servido.

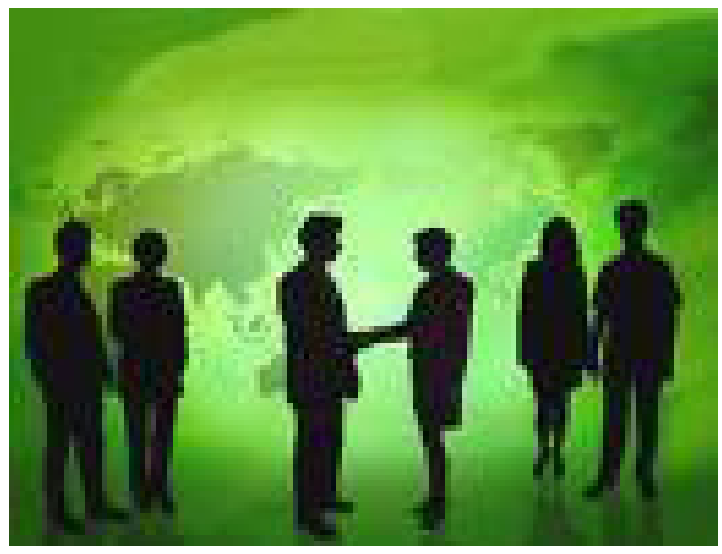

\section{¿EN QUÉ SE DIFERENCIAN LAS EMPRESAS CAPACES DE APRENDER DE OTROS TIPOS DE EMPRESAS?}

Las empresas capaces de aprender van construyendo su manera de ser y actuar de forma particular, según sus necesidades, experiencias y circunstancias particulares. La experiencia íntegra de cada una de ellas difícilmente sería útil para las otras. Sin embargo, sí es posible identificar los principios de aprendizaje que aplican en su manera de actuar y el camino que siguen en su proceso de transformación. 


\section{COMPARTIR UNA VISIÓN: EL FUTURO SE CONSTRUYE CADA DÍA}

Tal vez sea la consecuencia de uno de los principios fundamentales del aprendizaje organizacional: aprender.

Las empresas que aprenden han recorrido un largo camino hasta llegar a ser lo que son. Con seguridad, han dedicado tiempo y recursos a pensar colectivamente. Parte del aprendizaje común ha consistido en comprender el entorno en el que están inmersas. La idea de «lo que es válido para hoy puede no serlo para mańana», así una empresa que aprende estará continuamente expandiendo su capacidad para crear su futuro.

La estrategia, la estructura y la cultura de la empresa se forman dentro del sistema de aprendizaje. En consecuencia, han creado un conjunto de principios y valores que les mantiene «en la cuerda floja», suficientemente para aprovechar cualquier idea, no desechar nada sin valorarlo desde puntos de vista diferentes y asumir que el riesgo es una constante. Saben que su éxito depende, en parte, de ser y actuar en esta línea.

Integran todos sus recursos y ponen toda la organización al servicio de captar las oportunidades del mercado y ofrecer productos y servicios que satisfagan sus necesidades.

La construcción de una visión compartida es importante desde un principio, porque impulsa una orientación de largo plazo y el imperativo del aprendizaje.

\section{¿Qué hacer para construir el futuro día a día?}

- Analizar y discutir sobre el mercado colectivamente.

- Generar una cultura de flexibilidad, creatividad y aportación.

- Evaluar sus productos frente al mercado y sus competidores de forma continua.

\section{¿Qué dificultades han de superarse?}

- La desmotivación o desconfianza de los colaboradores.

- La tendencia del nivel directivo a imponer ideas.

- La prisa por pasar a la acción.

\section{LA CORRESPONSABILIDAD y COMPROMISO MUTUO}

Uno de los pilares fundamentales en la generación de la corresponsabilidad y el compromiso mutuo es el trabajo de los líderes cuando ejercen su influencia infundiendo energía para la creatividad y ayuda para compartir la visión, creando valores compartidos y estimulando el aprendizaje. Promueven la autonomía y la libertad para que las personas y equipos encuentren por sí mismos caminos y soluciones para trabajar de forma más efectiva. Cuando la gestión y la producción se acercan con una visión conjunta y comparten el poder, se establece un sistema que permite captar la innovación a través de la comunicación, el pensamiento colectivo e institucionalizando la búsqueda de la mejora continua de la empresa.

\section{¿Qué hacer para asegurar la}

corresponsabilidad y el compromiso

mutuo?

- Las personas deben ser estimuladas hacia la autonomía y la autogestión.

- Reconocer la necesidad y el saber de aprender en todos los niveles de la organización.

- Las personas son incluidas para compartir los éxitos, beneficios y fracasos.

\section{¿Qué dificultades han de superarse?}

- Las visiones del liderazgo tradicional.

- La acomodación de ser «hacedores» antes que «pensadores». 
- El temor a asumir los riesgos de las propias decisiones.

\section{CREER EN SU POTENCIAL CONJUNTO: TRABAJAR, APRENDER Y MEJORAR EN EL SENO DE EQUIPOS}

Ser conscientes de que las personas, con frecuencia, aprenden más y mejor en grupos y, en consecuencia, ponen en marcha proyectos que facilitan el aprendizaje grupal al tiempo que se trabaja.

Acostumbran a trabajar en equipos multidisciplinares complementarios que buscan ideas, soluciones y decisiones desarrolladas desde campos diferentes.

Una de las diferencias claves de la empresa que aprende es el aprendizaje colectivo. La confrontación de razonamientos e ideas ante un problema que precisa solución es un camino que ofrece mayor riqueza y seguridad. Es la vía que obliga al análisis colectivo y, en este proceso interactivo de colaboración para reducir la disonancia entre distintas posiciones, se comparan y evalúan opciones distintas: es el momento en el que se encuentran las decisiones más adecuadas. Se incorpora más información y se comparten colectivamente los principios y valores comunes a todos los miembros que sustentan la manera de actuar. Desde aquí cada persona y equipo construyen su autonomía basados en la ideología compartida.

Dixon (1994) propone cuatro aproximaciones que fundamentan el aprendizaje colectivo de las empresas:

1. Aprender es parte del trabajo y el trabajo lleva consigo aprender. Son funciones interrelacionadas que en la práctica no se pueden separar.

2. Aprender es sobre todo entender el sig- nificado de la experiencia que nosotros y otros tenemos en el mundo.

3. El aprendizaje en las empresas es el resultado de esfuerzos intencionados para aprender. No puede dejarse al azar.

4. Como colectivo, la empresa es capaz de aprender su propia manera de dar respuesta a sus problemas y debe confiar en sus recursos para poder solventar sus dificultades.

\section{¿Qué hacer para utilizar el potencial} conjuntamente?

- Pensar y analizar las situaciones en equipo.

- Los equipos deben ser multidisciplinarios, "pensadores y hacedores".

- Resolver los problemas entre todos los que están directamente implicados.

\section{¿Qué dificultades han de superarse?}

- La tendencia al individualismo.

- La toma de decisiones usando informaciones parciales.

- Baja implicación de los colaboradores.

\section{COMPARTIR LA INFORMACIÓN Y LAS IDEAS UTILIZANDO LA COMUNICACIÓN Y EL INTERCAMBIO DE FORMA FLEXIBLE Y CONTINUA}

Aprovechar cada oportunidad que se presenta en la propia realidad de la empresa para aprender en conjunto, a nivel individual y de grupo. El aprendizaje en la empresa se da más como respuesta a los problemas inmediatos, desequilibrios y dificultades que como consecuencia de un plan deliberado.

Desarrollar una estructura de funcionamiento en la que la comunicación de doble vía es el vehículo para desarrollarse y aprender. La escucha atenta, el respeto por las ideas 
y aportaciones de los otros y la libertad para expresar opiniones, se convierten en pilares básicos de su cultura.

Cuando los miembros de una organización comparten ideas o pensamientos esenciales que dan sentido a una forma de creencia, de visión, la capacidad de rendimiento y de respuesta es muy alta y optimiza el tiempo. Esto no implica que todas las personas compartan todas las ideas. La discrepancia es útil también para cuestionarse procesos y situaciones y poder mejorar, cambiar e innovar.

\section{¿Qué hacer para compartir la información y las ideas?}

- Disponer de un sistema de comunicación flexible y abierta.

- Trabajar de forma coordinada y utilizar el equipo para diseminar la información y compartir ideas.

- Generar creencias compartidas que faciliten el entendimiento mutuo.

- Debe haber un sistema de comunicación fluido.

\section{AVANZAR RÁPIDAMENTE: USAR EL SOPORTE, LA FACILITACIÓN Y EL APRENDIZAJE}

Los directores invierten la mayor parte de su esfuerzo en facilitar que los individuos y grupos adquieran altos niveles de autonomía y capacidad de gestión. Utilizan el entrenamiento para dar soporte y facilitar el autodesarrollo y el aprendizaje continuo de los colaboradores.

¿Qué hacer para avanzar de forma rápida?

- Generar y estimular un clima de aprendizaje continuo en general y de los otros.

- Dar soporte y facilitar el autodesarrollo de las personas y equipos.
- Transferir el conocimiento a otros y modificar su conducta incorporando los nuevos conocimientos.

- Disminuir la falta de habilidades para saber aprender.

\section{SE TRANSFORMAN: INNOVAN, INVENTAN Y CAMBIAN TRABAJANDO}

Cuando se trabaja con empresas que aprenden, es habitual ver a las personas, individualmente o en equipo, con una actitud permanente de búsqueda de nuevas ideas. Intercambian información, reinventan, discuten sobre los métodos, los productos y la forma de procesarlos. Crean al tiempo que trabajan.

El cambio rápido y constante del mercado y la mejora continúa son valores que comparten y que actúan de motor que estimula el poner a prueba nuevas maneras de organizar el trabajo y de aprender conjuntamente dentro y fuera de la organización.

¿Qué hacer para transformarse e innovar?

- Cuestionar lo presente, explorar nuevas ideas y oportunidades en todos los niveles de la organización.

- Remover barreras y bloqueos para aprender individualmente y en el entorno.

- Valorar y aceptar abiertamente todas las aportaciones.

\section{¿Qué dificultades han de superarse?}

- La inercia de lo que ya se sabe y se hace bien.

- La comodidad o falta de energía para resolver dificultades.

- La tendencia a desestimar algunas ideas o propuestas que no coincidan con la visión de la mayoría. 


\section{CONCLUSIONES}

Definitivamente, sí. Otras empresas lo han hecho y lo siguen haciendo. La cuestión más importante es decidir si se desea seguir este camino en la empresa y ponerse a trabajar. Las ventajas son indiscutibles, el proceso complejo y no precisamente rápido. Los factores críticos de éxito en su proyecto van a centrarse en:

- Generar significado colectivo de la misión de la empresa y la visión de lo que se espera que sea y logre en el futuro. La clave se centra en crear, definir y comprometerse con la misión en el nivel directivo y compartirla con todas las personas de la empresa. No hacerla o hacerlo parcialmente puede derivar en posiciones cínicas, fragmentadas y de desconfianza, $y$, en consecuencia, actuar de inhibidor del aprendizaje.

- Trabajar con un plan establecido desde la situación actual hasta las áreas que precisan cambios. Llegar a ser una empresa capaz de aprender es un proceso que no sucede de forma aleatoria. Requiere intervención organizada, por etapas. Entre las acciones más importantes se ha de decidir qué es necesario hacer, qué priorizar, cómo crear equipos de trabajo según los objetivos y los cambios que se desean conseguir, los recursos necesarios y con qué medidas se evaluarán los resultados.

- Aprender es un proceso de entrenamiento ligado al máximo posible al trabajo real. Aprender a aprender y promover la apertura hacia el aprendizaje es una idea que con frecuencia se comprende y hasta se comparte; el peligro es no saber cómo aprender a partir del trabajo y cómo integrar el aprendizaje adquirido fuera de él. Es tan importante querer aprender como saber cómo aprender.
- Dar soporte al aprendizaje colectivo y promover la apertura hacia el aprendizaje. Es una nueva manera de trabajar, difícil, dura y, a veces, precisa de valor, madurez y tiempo. Si la empresa en su conjunto comprende que ha de invertir tiempo, recursos, dar soporte y facilitar este proceso, los resultados son verdaderamente efectivos.

- Crear equipos y facilitar su aprendizaje para trabajar en equipo. Es la base fundamental del aprendizaje colectivo. Añaden valor por la complementariedad en la creatividad, la generación de ideas y la solución de problemas. También es un proceso progresivo de aprender a trabajar en equipo que precisa del soporte organizacional, de la apertura y sensibilidad de los líderes y de tiempo.

- Es el momento crucial para nuestro país que las empresas se preparen para afrontar los cambios que se avecinan a raíz de un nuevo escenario comercial. Aprender de otros modelos empresariales es la clave para hacer frente a los retos que significa la globalización, debemos partir de tener una visión empresarial compartida, la organización y el trabajo en equipo es importante para lograr metas y objetivos conjuntos.

\section{REFERENCIAS}

Aскоғғ, R. L.: Creating the Corporate Future. John Wiley and Sons, Nueva York, 1981.

Adler, N. J.: Time and Motion Regained. Harward Business Review, 71(1): págs. 97-108;1993.

Burgoyne, J., Pedler, M., Boydell, T.: Towards the Learnins Company: Concepts and Pradice. McGraw-Hill, UK, 1995. 
Dixon, N.: The Organizational Learning Cyele. How we can Learn Collectively. McGraw-Hill, Developing Orgarizations Series, UK, 1994.

Garratt, R.: Creating a Learning Organization. A guide to Leadership, Learning and Development. Cambridge: Director Books, 1990.

Garvin, D.A.: Building a Learning Organization. Harvard Bussinness Review, julio-agosto, 1993, pp. 78-91.

Pearn, M., Roderick, C., Mulrooney, C.: Learning Organizations in Practice. McGraw-Hill, UK, 1995.

Pedler, M., en: The Organizational Lear- ning Cyele. How we can Learn Collectively.

Dixon, Nancy, McGraw-Hill, Developing Organizations Series, UK, 1994.

SaInT-Onge, en: Learning Organizations in Pradice, Mc-Graw-Hill, CK, 1995, p. 51.

Senge, P.: La quinta disciplina: El arte y la práctica de la organización abierta al aprendizaje. Ed. Gránica, Barcelona, 1992. «Becomine a learning organization».

Swieringa, J., Wierdsma, A.: La organización que aprende. Madrid, Addison Wesley, 1995. 